\title{
Factors associated with medical complications after body art among Israeli adults: a retrospective study
}

\author{
Liat Korn ${ }^{1 *}$ (D) Hagit Bonny-Noach², Gideon Koren ${ }^{3}$ (D) and Rachel Nissanholtz-Gannot ${ }^{1}$ (D)
}

\begin{abstract}
Introduction: Body-art, including tattoos and piercings, is steadily increasing world-wide but with relatively limited reporting of adverse outcomes. The objective of the present study was to identify correlates that would facilitate a preventative strategy to minimize adverse effects of body-art.

Methods: We examined patterns of body-art, health risk and perceptions among 921 participants (54\% female, mean age of $35 ; \mathrm{SD}=10.8$ ) through in-person questionnaire.

Results: A significantly lower frequency of those with body-art acknowledged that not all venues (parlors, clinics, etc.) are safe in terms of health and hygiene $(84.7 \%$ t vs. $96.6 \%, p<.001)$ as compared to those without body-art. Similarly, knowledge of the need for a Ministry of Health certification was reported with lower frequency (77.2\% vs. $94.5 \%, p<.001)$ among those with body-art. Those who experienced medical complications reported higher frequencies of smoking cigarettes and hookah as well as using ecstasy (MDMA). The risk of medical complication after body-art was 4 times higher in those who used ecstasy ( $\mathrm{OR}=3.97 ; \mathrm{Cl} 1.0-14.4 ; p<0.05)$. In addition, it was more than 3 times higher for street or home tattooing as compared to studio or a licensed medical center (OR= 3.59; $\mathrm{Cl} 1.32-9.76 ; p<.01)$, as well as almost 3 times higher among those who did not receive information before performing body-art $(\mathrm{OR}=2.70 ; \mathrm{Cl} 1.05-6.92 ; p<.05)$ and who had somebody other than themselves decide on the body-art design $(\mathrm{OR}=2.68 ; \mathrm{Cl} 1.00-7.19 ; p<.05)$.

Conclusions: A targeted informational-preventative program should be developed, informed by the risks highlighted in this study. In addition, it would be necessary to draft policies related to regulation and enforcement in order to more effectively manage body-art service provision. The Ministry of Health should supervise and guide tattooists and practitioners regarding the health risks of body-art and offer training and raise awareness among potential clients.
\end{abstract}

Keywords: Body-art, Tattoos, Piercings, Health complications, Substance use

\section{Introduction}

Body-art, also known as body modification, body adornment or body composition [1, 2], is a phenomenon in which a person makes visible changes to their body [3,

\footnotetext{
*Correspondence: liatk@ariel.ac.il

'Department of Health Systems Management, School of Health Sciences, Ariel University, Ariel, Israel

Full list of author information is available at the end of the article
}

4] including tattooing, body piercing of various kinds, subdermal implants in various parts of the body, and surgical modification of bodily features. Studies in various countries have pointed to an increased prevalence of body-art [5-7], particularly among youth [8, 9]. In a 2012 public survey among 2016 Americans [10], 21\% reported having one tattoo or more, double the rate in 2008 (14\%). Other studies demonstrate that $25 \%$ of

\section{$\triangle B M C$}

(c) The Author(s). 2021 Open Access This article is licensed under a Creative Commons Attribution 4.0 International License, which permits use, sharing, adaptation, distribution and reproduction in any medium or format, as long as you give appropriate credit to the original author(s) and the source, provide a link to the Creative Commons licence, and indicate if changes were made. The images or other third party material in this article are included in the article's Creative Commons licence, unless indicated otherwise in a credit line to the material. If material is not included in the article's Creative Commons licence and your intended use is not permitted by statutory regulation or exceeds the permitted use, you will need to obtain permission directly from the copyright holder. To view a copy of this licence, visit http://creativecommons.org/licenses/by/4.0/ The Creative Commons Public Domain Dedication waiver (http://creativecommons.org/publicdomain/zero/1.0/) applies to the data made available in this article, unless otherwise stated in a credit line to the data. 
Americans and up to $47 \%$ in certain subpopulations have tattooed themselves [11].

Body-art via piercing, tattooing, and subdermal implants has potential health hazards. Studies have shown that about one-third of people who undergo tattooing develop some complications [12]. Those who undergo body piercing are also susceptible to health risks that derive from the procedure - its location on the body and the clinic where it is done [13]. The most common complications include local infections due to lack of training among those who execute the piercing and deficient hygiene at the clinic. For example, in the oral cavity, piercing may cause accumulation of bacteria and periodontal inflammation. In addition, piercing in the vicinity of the mouth may cause bleeding and nerve damage [14], and may trigger discharge of saliva [15]. Piercing of the tongue may cause gums to recede and, in extreme cases, teeth to fall out. Most pierced people with health concerns return to their body piercers or the Internet for applicable information and nonjudgmental care rather than to medical personnel [16].

In a 2011 study [17] of 1656 students, 78.3\% acknowledged the risk of tattooing or piercing, mainly in the forms of HIV-AIDS (60.3\%), hepatitis C (38.2\%), and tetanus (34.3\%). A recent study [18] recommended the development of an explanatory prevention system targeted at young people (especially male teenagers) regarding health and legal risks involving body-art. Presently, identification of at-risk individuals for adverse effects has been sparsely addressed. Any attempts at preventing such risks must identify factors and determinants typical of body-art. The objective of this research was to identify correlates that will facilitate a preventative strategy to minimize adverse body-art effects.

In the present study, we focused on people with bodyart and their attendant medical complications. Most of the research on complications of tattoos or piercings focuses on specific medical complications and their prevention [17-21] or the characteristics of the tattoos [2224] and piercings [20] contributing to the complications. However, in order to prevent medical complications following body-art, risk factors for complications that characterize these subjects need to be identified. As such, this study deals with an important public health hazard and contributes up-to-date data.

\section{Methods}

This is an observational, cross-sectional study aimed at comparing contributing factors for medical complication after body art.

\section{Procedure}

This cross-sectional study was approved by the university's IRB committee. The participants were recruited by research assistants, who were instructed to approach public places such as malls, train stations and tattooing and piecing venues throughout Israel. The inclusion criteria included adult (18 years or older) Hebrew speakers. A non-probability convenience sampling method was used in which the sample is taken from a group of people easy to contact or reach and was not intended to represent the adult population of Israel. As such, the purpose of this study was to identify factors associated with medical complications of body art and not its prevalence in the population. Hence, research assistants were instructed to approach people who underwent body art in tattooing and piecing venues. In Israel, tattoos are less common than in other developed countries due to religious prohibition. In order to avoid limited sampling of tattooed people, research assistants not only sought participants in public places in different cities in Israel, but also deliberately visited tattoo studios to approach tattooed people. In our case, this method is easily justified because tattoos are considered relatively rare.

\section{Research sample}

The sample comprised 921 participants (53.9\% women), with a mean age of 35 (age range: $19-84 ; \mathrm{SD}=10.8$ ) (Table 1). The participants included married (47.6\%), single (39.6\%), and divorced, separated or widowed $(12.9 \%)$ individuals. About half of the sample had children (55.4\%) and almost half held an academic degree (48.3\%). The sample included 412 subjects (44\% of the total) that underwent some form of body-art. Almost a quarter $(23.0 \%)$ of the sample were 25 years old or younger and more than half (52.6\%) were secular. The frequency of reporting body-art was lowest among those with far-above-average income (31.4\%).

\section{Research tool}

This study was based on an original questionnaire which was validated in a pilot study conducted on group of students before delivering it to the whole sample. The questionnaire was structured, self-reported, and covered sociodemographic details, knowledge of medicallyrelated risks associated with body-art, and substances use.

\section{Description of variables Body-art}

This variable refers to participants who have made at least one of the following changes: tattoo, piercing or subcutaneous transplant, based on the question: "Please report which type of body art you have (one or more, not including earlobes)." 
Table 1 Sociodemographic characteristics of the sample and frequency of performing body-art within each subgroup

\begin{tabular}{|c|c|c|c|c|}
\hline Variable & Value & Total sample $(N=921)$ & $\%$ of the sample & $\begin{array}{l}\% \text { of body-art } \\
(n=412)\end{array}$ \\
\hline \multirow[t]{2}{*}{ Gender } & Women & 496 & 53.9 & 52.3 \\
\hline & Men & 425 & 46.1 & 47.7 \\
\hline \multirow[t]{4}{*}{ Age } & $19-25$ & 207 & 23.0 & 52.2 \\
\hline & $26-30$ & 174 & 19.3 & 48.3 \\
\hline & $31-40$ & 299 & 33.2 & 52.5 \\
\hline & $41-84$ & 220 & 24.4 & 25.9 \\
\hline \multirow[t]{5}{*}{ Religion } & Secular & 476 & 52.6 & 56.9 \\
\hline & Traditional / nonreligious & 239 & 26.4 & 43.1 \\
\hline & Traditional / religious & 104 & 11.5 & 19.2 \\
\hline & Religious & 67 & 7.4 & 11.9 \\
\hline & Other & 19 & 2.0 & - \\
\hline \multirow[t]{5}{*}{ Income } & Far above average & 51 & 5.7 & 31.4 \\
\hline & Above average & 233 & 25.8 & 48.3 \\
\hline & Similar to average & 375 & 41.6 & 45.3 \\
\hline & Below average & 148 & 16.4 & 42.6 \\
\hline & Far below aveage & 95 & 10.5 & 45.3 \\
\hline
\end{tabular}

\section{Medical aspects concerning body-art: knowledge and attitudes}

Participants were asked whether they know of any risks concerning body-art (Yes/ No). In the Health and Hygiene Aspects, participants were asked, "Do you think the places (institutes, clinics and else) performing bodyart are safe in terms of health and hygiene?" Values were: 1 . Yes, all of them; 2. Probably some; 3 . Not sure; and 4. Don't know. Participants were asked if the places performing body-art are approved by the Ministry of Health. Values were: 1. Yes, all of them; 2. Probably some; 3. Not sure; and 4. Don't know. In addition, participants were asked whether written consent should be signed before undergoing a body-art procedure (Yes/ No/ Don't know).

\section{Obtaining health Hazard information}

Participants were asked whether they received information on health risks and complications involved in body art before performing the procedure (Yes/ No). Participants were also asked if they were requested to give written consent prior to the procedure (Yes/ No).

\section{Questions to those who underwent body-art}

Participants were asked if they suffered from any complications after the procedure (Yes/ No) as well as who made the decision regarding their tattoo design. Values were: 1 . Me - this is my original tattoo design; 2 . Me this is a tattoo design that I liked; 3. My spouse; 4. The tattooist; 5. My friends; and 6. I saw this tattoo design on someone else and I liked it; and 7. Other. In addition, another item was: Where was the body-art done? Values were 1 . On the street by a street artist; 2 . In the tattoo/ piercing studio; 3 . In a licensed medical center; 4 . At the artist's home; and 5. Other.

\section{Substance use}

Participants were asked in two different questions if they ever smoked cigaretttes or hookah. Values were: 1. I do not smoke; 2. Less than once a week; 3 . At least once a week, but not everyday; and 4. Everyday. Another item asked about binge drinking (as measured by the number of times in the last year five drinks or more were consumed in one event) and drunkness (as measured by number of times the participant was drunk in the last month). Values to both questions ranged from 1- never to 7 - more than twice a week. Participants were asked if they used recreational drugs such as cannabis, Ectasy (MDMA), and party drugs, etc. Values were: Any experience (Yes/No) and in the last month (Yes/No).

\section{Sociodemographic}

Participants were asked about their gender (woman/ man) and family status (single, married, divorced/ separated or widowed) and whether they have children.

\section{Education}

Participants were asked "What is your higher education?". Values ranged from 1. Highschool-education till 8. Master's degree and higher. Value 9 was other education. 


\section{Ethnic origin}

Participants were asked "Which ethnic origin / nationality best describes you?" Values were: 1. Ashkenazi / Western Europe; 2. Israeli Arab; 3. Spain / East; 4. Druze, 5. East Europe / Soviet Union / Russia; 6. Bedouin; 7. Ethiopia; 8. Mixed ethnic origins; and 9. Other.

\section{Religion}

Participants were asked to define their religious orientation. Values were: 1. Secular; 2. Traditional secular; 3. Traditional-religious; 4. Religious; 5. Haredi; and 6. Other: Please specify.

\section{Income}

Participants were asked to rate their personal income compared to other people their age. Values ranged on a five point Likert scale from 1 . well below average to 5 . A lot more than average.

\section{Data analysis}

The IBM SPSS Statistics 21 package was used to examine the data and perform the various analyses in this study. Significant differences in rates between subroups was determined by chi-square. Logistic regression was employed to identify significant risk factors related to medical complications of body-art comparing the odds ratios between those who experienced medical complications (study group) and those who did not (control group).

\section{Results}

Of all 921 participants in this study, 405 pariticants (44\%) underwent body art. Of those who underwent body art, $71.9 \%(n=291)$ got a tattoo, $26.9 \%$ a piercing $(n=109)$ and $1.2 \%(n=5)$ underwent subcutaneos implantation. Of those with body art, 18\% $(n=71)$ reported some type of medical complication (45- infection, 9trauma, 6- allergic reaction and others such as pain, scars or cysts).

The distribution of knowledge of body art medical risk by gender and by whether the participant did or did not undergo body-art is shown in Fig. 1.

Most participants $(91.0 \%)$ reported being aware that not all venues are medically and hygienically safe or certified by the Ministry of Health. Women reported more frequently than men that not all body-art venues are safe in terms of health and hygiene $(93.5 \%$ vs. $88.1 \%, p<.01)$ and they had significantly higher knowledge regarding infectious diseases $(66.7$ and $45.8 \%(p<0.001))$ as well as body-art caused bleeding or hematoma (52.0 and 34.8\%) compared to men. Those with body-art reported lower frequency that not all venues (parlors, clinics, etc.) are safe in terms of health and hygiene (84.7\%t vs. 96.6\%, $p<.001$ ) when compared to those without body-art. Similar findings were detected for certification by the Ministry of Health $(77.2 \%$ vs. $94.5 \%, p<.001)$. Those with body-art reported less knowledge that bleeding, or hematoma may be caused by body-art (37.4\%) compared to those without body-art $(43.4 \% ; p<0.05)$.

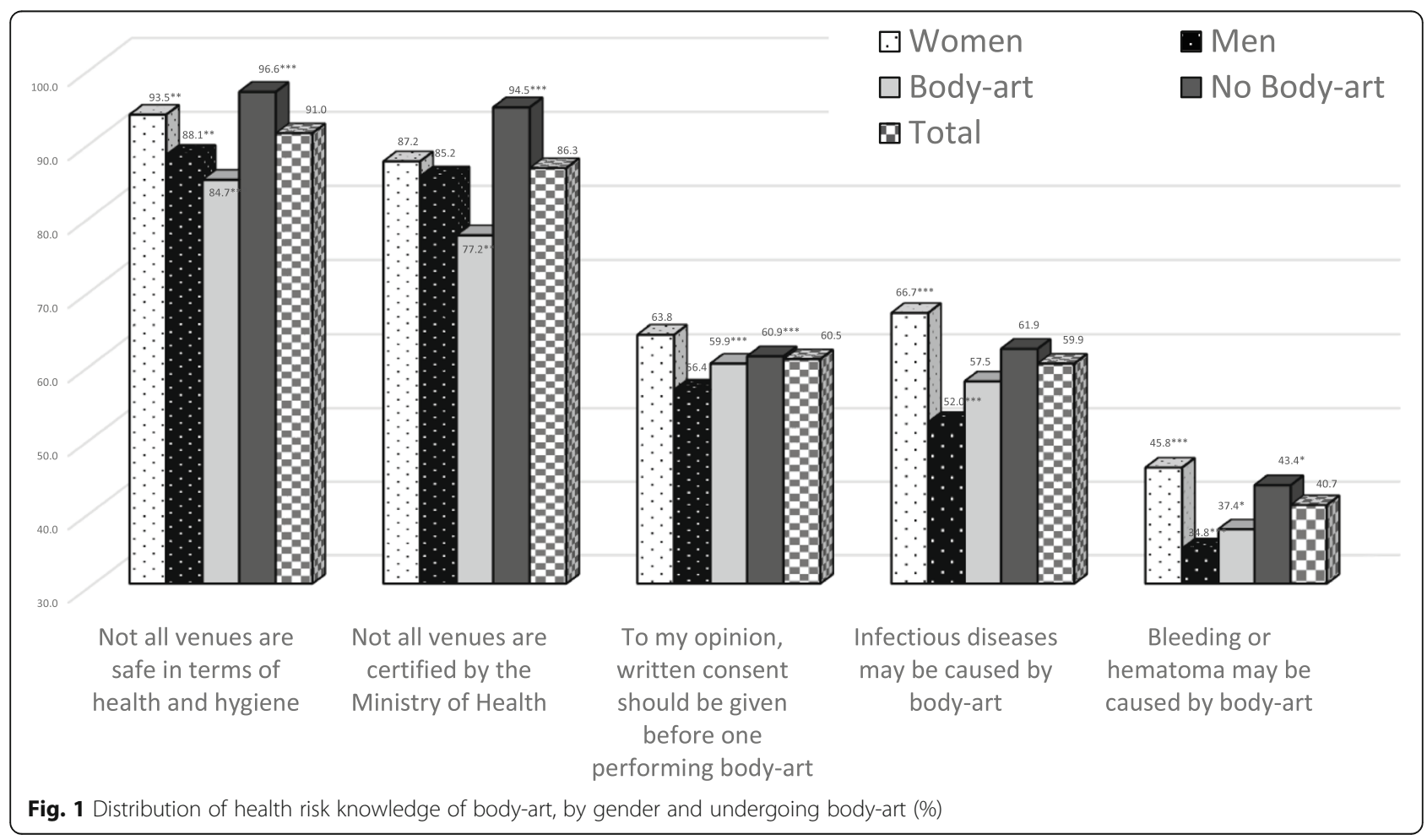


Table 2 presents the distribution of substance use frequencies between body-art groups, and complication groups. The table shows significant differences between those who underwent body-art and the non-body-art group in all substance uses, with higher frequencies for those with body-art: For example, cigarettes smoking $(56.6 \%$ vs. $34.3 \% ; p=0.000)$, binge drinking $(63.6 \%$ vs. $38.4 \% ; p=0.000)$, cannabis $(36.8 \%$ vs. $20.0 \% ; p=0.000)$, and party drugs such as Nice Guy $(8.3 \%$ vs. $3.8 \%$; $p=$ 0.005). Significant differences were also found between those who reported medical complications and those who did not among body-art groups in terms of cigarettes smoking $(68.3 \%$ vs. $55.3 \% ; p=0.040)$, hookah smoking $(46.7 \%$ vs. $27.2 \% ; p=0.026)$, and MDMA $(19.0 \%$ vs. $8.5 \%$; $p=0.014)$.

Table 3 presents the outcome of the logistic regression for association of different study variables with medical complications, among them, sociodemographic variables, substance use and ethical health risk considerations. Four variables had significant relations to medical complications after body-art. The stronger associations with medical complications were the use of MDMA ( $\mathrm{OR}=$ 3.97; CI 1.0-14.4; $p<0.05)$, the body-art venue ( $\mathrm{OR}=$ 3.59; CI 1.32-9.76; $p<.01)$, receiving information before the procedure $(\mathrm{OR}=2.70$; $\mathrm{CI} 1.05-6.92 ; p<.05)$, and who made the decision regarding the tattoo design $(\mathrm{OR}=2.68$; CI 1.00-7.19; $p<.05)$. The risk of medical complications after body-art was 4 times higher if a participant had used Ecstasy, and more than three times higher for street or home tattoos as compared to a studio or licensed medical center location. The risk was almost 3 times higher among those who did not receive information before, and when somebody else decided the design of the body art.

\section{Discussion}

This study provides a snapshot of different health risks including knowledge, substance use and ethical aspects concerning medical complications after undergoing body-art. Based on a structured self-reported questionnaire, the results show large differences between participants who underwent body-art and those who did not regarding knowledge of health risks and medical complications as an outcome. Our findings on participant knowledge of health risks and complications indicate scant knowledge among both those who had experience and those who lacked it. Infections and inflammation, although common complications $[25,26]$, are reported as a possible complication by only $60 \%$ of the participants. In addition, only $40 \%$ of participants mentioned bleeding or hematoma as possible complications, with women and those who did not undergo any body-art having significantly higher knowledge than men or those who underwent body-art. A survey among students in Italy [17] also revealed partial knowledge regarding medical complications after performing body-art. This point deserves emphasis: it shows that the population that engages in body-art is inadequately aware of the health implications and complications of these procedures. This invokes concern about health ethics in relation to these procedures. It is of importance that level of knowledge of body-art risk should not vary and not directly be associated with perceptions regarding undergoing body-art. Indeed, the desire to get body-art may be stronger than the fear of its complications. In our study, women showed higher knowledge regarding medical complications than men, with those who underwent body-art knowing more about this aspect than those who did not. This may be partially explained by their higher engagement in body-art [17], as showed in our results.

Table 2 Distribution of substance use frequencies between body-art groups, and complications groups (\%)

\begin{tabular}{|c|c|c|c|c|c|c|}
\hline \multirow[t]{2}{*}{ Variable } & \multicolumn{3}{|c|}{ Among all sample } & \multicolumn{3}{|c|}{ Only among body-art group } \\
\hline & $\begin{array}{l}\text { Body-art } \\
(n=399 \sim \\
410)\end{array}$ & $\begin{array}{l}\text { No body-art } \\
(n=472 \sim \\
502)\end{array}$ & $* P$ & $\begin{array}{l}\text { Medical } \\
\text { complications } \\
(n=56 \sim 60)\end{array}$ & $\begin{array}{l}\text { No medical complications ( } n=342 \sim \\
349 \text { ) }\end{array}$ & ${ }^{*} P$ \\
\hline $\begin{array}{l}\text { Cigarette smoking (any } \\
\text { frequency) }\end{array}$ & $56.6 \%$ & $34.3 \%$ & 0.000 & $68.3 \%$ & $55.3 \%$ & 0.040 \\
\hline $\begin{array}{l}\text { Hookah smoking (any } \\
\text { frequency) }\end{array}$ & $30.4 \%$ & $17.5 \%$ & 0.000 & $46.7 \%$ & $27.2 \%$ & 0.026 \\
\hline Binge drinking (past year) & $63.6 \%$ & $38.4 \%$ & 0.000 & $71.7 \%$ & $64.3 \%$ & NS \\
\hline Drunkenness (past month) & $42.2 \%$ & $20.0 \%$ & 0.000 & $63.3 \%$ & $41.8 \%$ & NS \\
\hline Cannabis (any use) & $36.8 \%$ & $20.0 \%$ & 0.000 & $44.6 \%$ & $36.0 \%$ & NS \\
\hline Ecstasy (MDMA) (any use) & $9.8 \%$ & $3.4 \%$ & 0.000 & $19.0 \%$ & $8.5 \%$ & 0.014 \\
\hline $\begin{array}{l}\text { Party drugs } \\
\text { Nice Guy (any use) }\end{array}$ & $8.3 \%$ & $3.8 \%$ & 0.005 & $15.8 \%$ & $8.2 \%$ & 0.067 \\
\hline Party drugs Cathinone (any use) & $6.5 \%$ & $1.9 \%$ & 0.001 & $10.5 \%$ & $5.8 \%$ & NS \\
\hline
\end{tabular}

*Chi-square significant for differences between independent groups of BM and Medical complications 
Table 3 Logistic regression to identify risk factors related to medical complications of body-art performance

\begin{tabular}{|c|c|c|c|c|}
\hline \multirow[t]{2}{*}{ Variable } & \multirow[t]{2}{*}{ Values } & \multirow[t]{2}{*}{ OR } & \multicolumn{2}{|c|}{ 95\% Confidence Interval for } \\
\hline & & & $\begin{array}{l}\text { Lower } \\
\text { Bound }\end{array}$ & $\begin{array}{l}\text { Upper } \\
\text { Bound }\end{array}$ \\
\hline Gender & Female $=0$, Males $=1$ & 0.81 & 0.32 & 2.06 \\
\hline Age (median split) & Older ... younger & 0.47 & 0.18 & 1.23 \\
\hline Religion & Married $=0$, Single, Divorced $=1$ & 0.88 & 0.36 & 2.15 \\
\hline Income & Yes $=0, \mathrm{No}=1$ & 1.15 & 0.74 & 1.79 \\
\hline Ecstasy (MDMA) & Never $=0$, Ever $=1$ & $3.97^{*}$ & 1.09 & 14.4 \\
\hline Venue of body-art & $\begin{array}{l}\text { Studio or a licensed medical center }=0 \text {, Street, tattooist home }= \\
1\end{array}$ & $3.59 * *$ & 1.32 & 9.76 \\
\hline $\begin{array}{l}\text { Received information before the } \\
\text { procedure }\end{array}$ & Yes $=0, \mathrm{No}=1$ & $2.70^{*}$ & 1.05 & 6.92 \\
\hline Who decided about the tattoo design & $\mathrm{Me}=0$, All others $=1$ & $2.68^{*}$ & 1.00 & 7.19 \\
\hline Cigarette smoking & Never $=0$, Ever $=1$ & 1.31 & 0.50 & 3.47 \\
\hline Hookah smoking & & 1.95 & 0.80 & 4.73 \\
\hline Binge drinking & & 1.13 & 0.41 & 3.06 \\
\hline Drunkenness & & 0.73 & 0.29 & 1.88 \\
\hline Cannabis & & 1.75 & 0.51 & 5.96 \\
\hline Party drugs- Nice Guy & & 0.35 & 0.09 & 1.33 \\
\hline Party drugs- Cathinone & & 0.91 & 0.21 & 4.01 \\
\hline Written consent before body-art & Yes $=0, \mathrm{No}=1$ & 0.84 & 0.33 & 2.15 \\
\hline$R^{2}$ Nagelkerke & $23.2 \%$ & & & \\
\hline $\mathrm{N}$ & 272 & & & \\
\hline
\end{tabular}

As discussed in the literature, health risk behaviors such as substance use are more common among those who have undergone body-art or those experiencing complications. Tattooed and pierced Israeli individuals reported more smoking, binge drinking and cannabis use [24]. Our findings also include the relations of substance use to medical complications in tattooed and pierced individuals. In our results, participants who experienced medical complications among those who underwent body-art reported more cigarette smoking, hookah smoking and MDMA. In Israel, body-art is much less prevalent than in Europe or North America, possibly due to the prevalence of religious prohibition against body-art.

The differences between those who underwent bodyart and those who did not suggest that people who modify their bodies more frequently display interest and curiosity as their initial feelings toward others who have done the same. They also report that they placed more adornments in exposed parts of the body than do people who did not undergo body-art modification. The present findings reveal that the risk of experiencing medical complications after body-art are higher in those who have used MDMA, were tattooed in the street or at the tattooist's home (rather than in a studio or licensed medical center), did not receive information before the procedure, and whose tattoo design was selected for them. As such, a targeted informational-preventative program should be developed, taking into account the risks highlighted by this study. In addition, policies related to regulation and enforcement should be drafted in order to ensure safer body-art services.

However, this research limitations that should be noted, with one stemming from its convenience sampling method: research assistants were told to approach public places as well as tattoo and piercing venues. That may create a selection bias and can make generalization to the Israeli adult population difficult. Although the main disadvantage of this method is its inability to achieve a measure of prevalence in a population, this was not the purpose of the current research. In fact, non-probability sampling methods were used in studies on tattooing in Italy [17], Malaysia [27], and Texas [28].

Another limitation stems from the self-reported questionnaire which may suffer from wish bias and social desirability. The recommendations expressed above include the development of a focused array of Ministry of Health-derived preventive information strategies oriented at young people (young men in particular) intending to reduce possible body-art health risks. Additional 
recommendations include drafting relevant policies, along with explicit laws pertaining to body-art - as exist in other countries, as well as closer supervision of these venues. For example, in Italy, a collaborative educational program among body artists was proposed to share information about body-art in general, including inherent risks, encouraging young adults to contemplate their decisions carefully in advance [17]. In Tanzania, registered centers were recommended as well as continued health education and counseling on the risk of complications [19]. Knowledge of body-art complications should be emphasized, not only for health professionals but also the general population [27].

\section{Conclusions}

Significant differences were found between participants who underwent body-art and those who did not regarding knowledge toward health risks and medical complications. This raise concerns that those who engage in body-art are inadequately aware of the medical implications and complications of these procedures. These findings suggest that undergoing body-art during adolescence or young adulthood may create a situation that could spiral out of control in terms of decisionmaking and, therefore, consequential medical complications. As such, this study advocates for changes in policy: tougher regulation of these venues, with emphasis on compulsory provision of information about complications, and ascertainment that such knowledge is being transmitted and received, along with obtaining informed consent for the procedure. The Ministry of Health should supervise and guide tattooists and practitioners concerning the medical risks of performing body, offering training and raising awareness among potential clients.

\section{Abbreviations}

Cl: Confidence interval; IRB: Institutional review board; MDMA: Methylene dioxy meth amphetamine; OR: Odds ratio; SD: Standard deviation

\section{Acknowledgments}

The authors declare no conflict of interest. We would like to thank the research assistants for their willingness to contribute to this research.

\section{Authors' contributions}

LK analyzed the data, HBN was responsible for data collection, GK edited the manuscript and RNG was responsible for project development. All authors wrote the manuscript and approved the final manuscript.

\section{Funding}

This research did not receive any specific grant from funding agencies in the public, commercial, or not-for-profit sectors.

\section{Availability of data and materials}

The datasets analyzed during the current study are available from the corresponding author on reasonable request.

\section{Declarations}

Ethics approval and consent to participate

All procedures performed in studies involving human participants were in accordance with the ethical standards of Ariel University's research ethics committee and with the 1964 Helsinki declaration and its later amendments or comparable ethical standards. Informed consent was obtained from all individual participants included in the study.

Consent for publication

Not applicable.

\section{Competing interests}

All authors declare that they have no competing interests.

\section{Author details}

'Department of Health Systems Management, School of Health Sciences, Ariel University, Ariel, Israel. ${ }^{2}$ Department of Criminology, School of Social Sciences, Ariel University, Ariel, Israel. ${ }^{3}$ Adelson Faculty of Medicine, Ariel University, Ariel, Israel and Motherisk Israel Program, Shamir Hospital, Be'er Ya'akov, Israel.

Received: 22 May 2020 Accepted: 8 June 2021

Published online: 01 September 2021

References

1. Chivers L. Body adornment: piercings and tattoos. Nurs Stand. 2002;16(34): 41-5. https://doi.org/10.7748/ns2002.05.16.34.41.c3192.

2. Naudé L, Jordaan J, Bergh L. "My Body is My Journal, and My Tattoos are My Story": South African Psychology Students' reflections on tattoo practices. Current Psychology. 2019;38(1):177-86.

3. Albin DD. Making the body (w)hole: a semiotic exploration of the body modification. Psychodynamic Pract. 2006;12(1):19-35. https://doi.org/10.1 080/14753630500471960.

4. Dey A, Das K. Why we tattoo. Exploring the motivation and meaning. Anthropol. 2017:5(1):2-6.

5. Armstrong ML, Roberts AE, Owen DC, Koch JR. Contemporary college students and body piercing. J Adolesc Health. 2004;35(1):58-61. https://doi. org/10.1016/S1054-139X(03)00338-0.

6. Armstrong ML, Roberts AE, Owen DC, Koch JR. Toward building a composite of college student influences with body art. Issues Compr Pediatr Nurs. 2004;27(4):277-95. https://doi.org/10.1080/01460860490884183.

7. Mayers $\mathrm{L}$, Chiffriller $\mathrm{S}$. Sequential survey of body piercing and tattooing prevalence and medical complication incidence among college students. Arch Pediatr Adolesc Med. 2007;161(12):1219-20. https://doi.org/10.1001/a rchpedi.161.12.1219-b.

8. Bercaw-Pratt J, Santos X, Sanchez J, Ayensu-Coker L, Nebgen D, Dietrich J. The incidence, attitudes and practices of the removal of pubic hair as a body modification. J Pediatr Adolesc Gynecol. 2012;25(1):12-4. https://doi. org/10.1016/j.jpag.2011.06.015.

9. Bui E, Rodgers R, Cailhol L, Birmes P, Chabrol H, Schmitt L. Body piercing and psychopathology: a review of the literature. Psychother Psycosomatics. 2010;79(2):125-9. https://doi.org/10.1159/000276376.

10. Harris P. 2012. http://www.vanishingtattoo.com/tattoo_facts.htm. Accessed 08 May 2020.

11. Braveman S. The Harris Poll;2012. One in Five US Adults Now Has a Tattoo. Available at: https://www.prnewswire.com/news-releases/one-in-five-us-a dults-now-has-a-tattoo-140123523.html. Accessed 08 May 2020.

12. Klugl I, Hiller KA, Landthaler M, Baumler W. Incidence of health problems associated with tattooed skin: a nation-wide survey in German-speaking countries. Dermatology. 2010;221(1):43-50. https://doi.org/10.1159/000292627.

13. Ressin M. Piercing insights. The Nurse in Israel. 2015;187:32-8 (in Hebrew).

14. Uppal RS, Kapu S, Kapur J, Singh A, Kapur G. Oral piercing: a deleterious vogue. J Contemp Dent. 2012;3(2):1-8.

15. Botchwqay C, KuC I. Tongue piercing and associated tooth fracture. J Dent Assoc. 1998;64:803-5.

16. Armstrong ML, Koch JR, Saunders JC, Roberts AE, Owen DC. The hole picture: risks, decision making, purpose, regulations, and the future of body piercing. Clin Dermatol. 2007;25(4):398-406. https://doi.org/10.1016/j. clindermatol.2007.05.019. 
17. Quarante A, Napoli C, Fasano F, Montagna C, Caggiano G, Montagna MT. Body piercing and tattoos: a survey on young adults' knowledge of the risks and practices in body art. BMC Public Health. 2011;11(1):774. https://doi. org/10.1186/1471-2458-11-774.

18. Nissanholtz-Gannot, Bonny-Noach, Liat K. Knowledge attitudes and behavior patterns regarding body modifications in Israel: tattoos, piercing and subcutaneous implants. Soc Issues Israel. 2018;25:180-208 in Hebrew.

19. Chacha CE, Kazaura MR. Body-art practices among undergraduate medical university students in Dar Es Salaam, Tanzania, 2014. Ind J Dermatol. 2015; 60(2):212. https://doi.org/10.4103/0019-5154.152567.

20. Covello F, Salerno C, Giovannini V, Corridore D, Ottolenghi L, Vozza I. Piercing and Oral health: a study on the knowledge of risks and complications. Int J Environ Res Public Health. 2020;17(2):613. https://doi. org/10.3390/ijerph17020613.

21. Rogowska P, Szczerkowska-Dobosz A, Kaczorowska R, Słomka J, Nowicki R. Tattoos: evaluation of knowledge about health complications and their prevention among students of Tricity universities. J Cosmet Dermatol. 2018; 17(1):27-32. https://doi.org/10.1111/jocd.12479.

22. Bassi A, Campolmi P, Cannarozzo G, Conti R, Bruscino N, Gola M, et al. Tattoo-associated skin reaction: the importance of an early diagnosis and proper treatment. Biomed Res Int. 2014;2014:1-7. https://doi.org/10.1155/2 014/354608.

23. Farley CL, Van Hoover C, Rademeyer CA. Women and tattoos: fashion, meaning, and implications for health. J Midwifery Women's Health. 2019; 64(2):154-69. https://doi.org/10.1111/jmwh.12932.

24. Kluger N. Tattoo-associated uveitis with or without systemic sarcoidosis: a comparative review of the literature. J Eur Acad Dermatol Venereol. 2018; 32(11):1852-61. https://doi.org/10.1111/jdv.15070.

25. Ochsenfahrt C, Friedl R, Hannekum A, Schumacher A. Endocarditis after nipple piercing in a patient with a bicuspid aortic valve. Soc Thorac Surg. 2001;71(4):1365-6. https://doi.org/10.1016/S0003-4975(00)02273-6.

26. Ranga N, Jeffery JA. Unexpected outcome: Body piercing with fatal consequences. BMJ Case Rep. 2011. https://doi.org/10.1136/bcr.05.2010.3020.

27. Aizi NA, Joyce M, Evangeline J, Samarathunga KG. Attitude towards body arts (Tattoos and Body Piercing) and the knowledge on its complications among medical students: a cross-sectional study. Adv Biomed Sci. 2019;4(1):13.

28. Stuppy DJ, Armstrong ML, Casals-Ariet C. Attitudes of health care providers and students towards tattooed people. J Adv Nurs. 1998;27(6):1165-70. https://doi.org/10.1046/j.1365-2648.1998.00626.x.

\section{Publisher's Note}

Springer Nature remains neutral with regard to jurisdictional claims in published maps and institutional affiliations.

Ready to submit your research? Choose BMC and benefit from:

- fast, convenient online submission

- thorough peer review by experienced researchers in your field

- rapid publication on acceptance

- support for research data, including large and complex data types

- gold Open Access which fosters wider collaboration and increased citations

- maximum visibility for your research: over $100 \mathrm{M}$ website views per year

At BMC, research is always in progress.

Learn more biomedcentral.com/submissions 